\title{
Breast Self-examination Practice and Associated Factors Among Women of Reproductive Age in Adama Town, Oromia Regional State, Ethiopia
}

\author{
Lemlem Kebede ${ }^{1, *}$, Meyrema Abdo², Abebe Megerso $^{2}$ \\ ${ }^{1}$ Department of HIV/AIDS Prevention and Control Office, Adama Science and Technology University, Adama, Ethiopia \\ ${ }^{2}$ Departments of Public Health, Adama Hospital Medical College, Adama, Ethiopia \\ Email address: \\ lemlemkebe@gmail.com(L. Kebede),meyremaabdo@gmail.com (M. Abdo), abemegerso@gmail.com (A. Megerso) \\ ${ }^{*}$ Corresponding author
}

To cite this article:

Lemlem Kebede, Meyrema Abdo, Abebe Megerso. Breast Self-examination Practice and Associated Factors Among Women of Reproductive Age in Adama Town, Oromia Regional State, Ethiopia. Central African Journal of Public Health. Vol. 7, No. 4, 2021, pp. $227-235$. doi: 10.11648/j.cajph.20210704.22

Received: July 23, 2021; Accepted: August 19, 2021; Published: August 31, 2021

\begin{abstract}
Breast Self-Examination is the process where by a woman examines her own breasts by seeing and feeling with fingers to detect breast lump or swelling. More than $90 \%$ cases of breast cancer are detected by women themselves. Poor practice of breast self-examination is usually associated with patient delay. The five-year survival rate for a localized breast cancer is $84 \%$. Community based breast self-examination practice is low in the country specifically in the present study area. Thus this study aimed to assess breast self-examination practice and associated factors among women of reproductive age in Adama Town, Oromia Regional State, Ethiopia in 2017EC. This Community based- cross sectional quantitative study was conducted using a random sample and multistage sampling procedure by administering pretested structured questionnaire to the population of 765 reproductive age women. The collected data were cleaned, coded and entered into Epi-Info version 7 and exported to SPSS version 20 for analysis. Descriptive statistics, bivariate and multivariable logistic regression were computed. Adjusted odds ratio (AOR) with $95 \%$ confidence interval (CI) was used to assess the association among study variables. This study indicated that the overall prevalence of breast self- examination practice was $51.4 \%$ with $95 \%$ CI $(48.1,55.2)$. Factors associated with breast self-examination practice were above secondary education (AOR, 6.38; 95\% CI: 2.87, 14.16), secondary education (AOR, 5.03; 95\% CI: 2.24, 11.30), knowing someone suffering from breast cancer (AOR, 1.98, 95\% CI: 1.27, 3.09), and fear of breast cancer from family history (AOR, 12.38, 95\% CI: 6.36, 24.10) were having statically significant and positive association with breast self-examination practice. This study revealed that breast self-examination practice was high. Oromia Regional Health Bureau, Adama Town Health Office, women's and children's affair offices and other stake holders should disseminate teaching materials that address the benefit of breast self-examination practice. Health professionals should teach the community about the advantage of breast self-examination practice through mass media, awareness raising campaigns, and celebration of breast cancer day.
\end{abstract}

Keywords: Breast Self-examination Practice, Breast Cancer, Adama, Ethiopia

\section{Introduction}

Breast Self-Examination (BSE) is a technique in which a woman examines her own breasts by seeing and feeling with fingers to detect breast lump [1]. More than $90 \%$ of cases of breast cancer can be detected by women themselves. This reality stresses the importance of breast self-examination (BSE) as the key breast cancer detection mechanism [2]. The five-year survival rate for a localized breast cancer is $84 \%$, with regional spread of $71 \%$ and with distant metastases of only 18\% [3]. Between 2005 and 2015 cancer cases increased by $33 \%$. Breast cancer was the leading cause of cancer deaths and DALYs for women (523, 000 deaths and 15.1 million DALYs) [4]. Breast cancer has become the most frequently diagnosed cancer among women in 140 of 184 countries worldwide and it represents one in four of all cancer cases in 
women [5].

Cancer has been identified as a major public health problem in both developed and developing nations because of its high incidence-prevalence rate, over-burdening the health system and direct medical expenditure [6]. Asia and Africa have experienced a more rapid rise in the annual incidence rate of breast cancer than that of North America and Europe. About $24 \%$ of all BC was diagnosed with in the Asia-Pacific region with the greatest number of those occurring in China 46\%, Japan 14\%, and Indonesia 12\% [7] Breast cancer incidence in Africa continues to increase and is projected to double by 2050 [8]. The majority of cancer cases in Africa are diagnosed at an advanced stage of the disease because of lack of screening and early detection services as well as limited awareness of early signs and symptoms of cancer [9].

Despite this increasing burden of breast cancer, females are not aware of this easy method of early breast cancer screening technique. In Sweden the ten most common forms of cancer constitute fully $75 \%$ of all cancer cases. Breast cancer and prostate cancer are by far the most commonly occurring types of cancer accounting for more than $30 \%$ of all cancer cases [10]. Indian National Cancer Registry Programme shows that breast cancer is the leading cancer in women at present in 11 out of 13 population based cancer registries in the country [11]. Studies from Tunisia, Egypt, and Morocco reported that North Africa has a greater proportion of inflammatory breast cancer. In Kenya and Nigeria BC at advanced stage of the disease accounts $89.6 \%$ and $72.8 \%$ of $\mathrm{BC}$ patients respectively [12]. Despite this growing cancer burden in Africa, cancer continues to receive a relatively low public health priority.

It is mainly because of limited resources and other pressing public health problems including communicable diseases such as acquired immunodeficiency syndrome (AIDS)/(HIV) infection, malaria, and tuberculosis [13]. A major worry about breast cancer in Nigeria is the continuous rise in the number of cases and deaths. Breast cancer has been reported to have an early onset among Nigerian women $[14,15]$. The 5 years survival rate of breast cancer in Nigeria is less than $10 \%$ compared with more than $70 \%$ in Western European and North America [16]. Incidence of cancer in developing countries like Ethiopia which are not prepared to control the case is rising at an alarming rate. The worst aspect of the disease in Ethiopia is that there is very little or almost no complete information on any aspect of the problem. In addition there are no control and prevention programmes against the disease [4]. A Study conducted in 2015 In Tikur Anbessa Specialized Hospital oncology center on the pattern of cancer in Ethiopia from 1998 to 2010 shows that breast cancer is found to be the second most common malignancy [17].

Another Study conducted in Gondar Hospital shows that cervical cancer, breast cancer and lymphomas are the commonest cancers in females [18]. Similar Study conducted In Tigray Region shows that breast cancer is the most common cancer constituting about $32.33 \%$ In Patient Department (IPD). Over all cancer trend is increasing with breast cancer as the first leading cause of morbidity and mortality followed by the unspecified malignant neoplasm [19]. A study conducted among Malaysian women shows that only $54 \%$ of the study's population had ever practiced breast self-examination [20]. This study reveals that BSE practice is significantly related to race, age, marital status, education, knowledge about $\mathrm{BC}$ and its screening program [21]. A survey conducted in Cameroon shows the only 6 in every 10 woman, and $59.17 \%$ claimed to know how to practice breast self-examination, Only $35 \%$ of them practiced breast self-examination monthly; $40 \%$ of the respondents had never practiced breast self-examination at all [22]. In the same manner, a Study conducted in Shah Alam, Malaysia indicates that BSE was more likely to be done among women aged above or equal to 45 years in comparison to those aged 18-29 years [23]. A related study conducted among Saudi women shows that age, educational level, family history of breast cancer and knowledge, was highly significant with BSE [24]. A related study conducted in Ajman reveals that married female had significantly higher frequency of BSE practice than unmarried ones, but has no significant association with breast cancer risk perceptions [25].

Similarly a study conducted among Jordanian women shows that older women with above high school education and those with health insurance practiced breast self-examination significantly more than other women [26]. On the contrary, A study conducted in Angola reveals that the level of education did not influence the knowledge of breast self-examination practice [27]. A Study conducted among Iranian women shows there is significant relationship between breast selfexamination practice and job [28]. A study conducted in India reveals that there is a significant positive co-relation among knowledge of breast cancer susceptibility; seriousness and breast self-examination benefit [29]. A Study conducted in Nigeria shows that the attitude of the respondents to health information on breast self-examination was positive with a fairly high degree of acceptability of the idea [30]. A related study conducted among Turkish women shows that women who had a family history of breast cancer are almost 12 times more likely to perform BSE than those who have no such family history [31] Another Study done in Angola shows women with a family history of breast cancer are more informed and seek more information about breast selfexamination practice [27]. A similar study conducted in West Gojjam Zone of Amhara regional state Ethiopia shows that getting information on breast self-examination from health professional, discussion with families on the importance of breast self-examination, and the history of breast examination by health professional were the factors found to be associated with breast self-examination practice [32]. Astudy conducted in Ondo State Nigeria shows that only $25 \%$ of the respondents practiced breast self-examination every month [33]. A study conducted in Kenya reveals that $40.9 \%$ of the respondents were practicting breast self-examination monthly [34]. A study 
conducted in Kafa Zone, Ethiopia indicated that $73.07 \%$ of the respondents ever performed BSE [35]. A related study conducted in Adama Science and Technology University shows that about two fifth $(39.4 \%)$ of the respondents had practiced BSE, among these only $9.7 \%$ of them practiced the BSE on monthly basis [36].

Similar study conducted in Mekelle Town shows that only $53.6 \%$ of the respondents ever practiced breast selfexamination [2]. A study conducted in Addis Ababa show that marital status was significantly associated with the practice of breast self-examination [37]. In general, breast cancer is the major public health concern in developed and developing world. Breast cancer is almost the leading cause of death and DALY among female population in the world and in developing countries such as Asia, Africa and SubSaharan Africa. The majority of the patients would come to the health facilities in late stage of the disease with no treatment option.

\section{Methods and Materials}

\subsection{Study Area and Period}

The study was conducted in Adama town, east shewa zone, Oromia regional state, Ethiopia. Based on the 2007 census conducted by the central statistical agency of Ethiopia the 2017 projected population of the city was 341,796 of which 170,953 were female and 87,476 were found in reproductive age groups. Adama was found in Oromia region; $100 \mathrm{~km}$ away from the capital, Addis Ababa, towards the eastern part of the country [38]. The city has 1 government hospital, 7 government health centers, four private hospitals, and 94 private clinics with different levels [14]. The study was conducted between October, 1/2017and December, 31, 2017.

\subsection{Study Design}

Community based cross sectional quantitative study design was used.

\subsection{Population}

\subsubsection{Source Population}

All Women of reproductive age who live in Adama town

\subsubsection{Study Population}

Women of reproductive age who were selected in the selected sub cities and Keble households during the time of study and fulfilled the inclusion criteria were involved in the study.

\subsection{Inclusion and Exclusion Criteria}

\subsubsection{Inclusion Criteria}

All Women of reproductive age who live more than or equal to 6 months in Adama town and volunteer to participate in the study and present at the time of study period were included in this study.

\subsubsection{Exclusion Criteria}

Any women of reproductive age who are ill and cannot communicate with the data collector, Women who were diagnosed to have breast cancer, Woman who had mastectomy and those who refused to participate in the study were excluded from the study.

\subsection{Sample size Determination and Sampling Procedures}

\subsubsection{Sample Size Determination}

The sample size was determined by using a formula for estimation of a single population proportion. In community based cross sectional studies conducted in Mekelle town, Ethiopia, breast self-examination practice was $29.5 \%$ among women of house hold heads. Sample size was computed using a 95\% confidence level, $4 \%$ precision, $29.5 \%$ prevalence of current breast selfexamination practice in Mekelle town [4]. 1.5 design effect and $5 \%$ of the sample size was added to compensate for non-response rate.

$$
\mathrm{n}=\frac{(\mathrm{Z} \alpha / 2)^{2} * \mathrm{p}(1-\mathrm{p})}{(\mathrm{d})^{2}}
$$

Where:

$\mathrm{n}=$ number of reproductive age women to be interviewed

$\mathrm{p}=$ proportion of reproductive age women who practice breast self-examination $(29.5 \%)$

$\mathrm{d}=$ estimated margin of error for the study, $4 \%$ and

$\mathrm{Z} \alpha / 2=$ the standard normal distribution $\mathrm{z}$ value of 1.96 (at $95 \%$ level of confidence).

$$
\begin{gathered}
\mathrm{n}=\frac{1.96^{2} * 0.295(1-0.295)}{(0.04)^{2}} \\
\mathrm{n}=499
\end{gathered}
$$

$\mathrm{n}=(499)$ multiplied by 1.5 design effect and $5 \%$ nonresponse rate was added to the sample. Then the optimum sample size required was 786 .

\subsubsection{Sampling Procedure}

A multi-stage sampling technique was used to select the respondents of the study. From six sub cities of Adama town four sub cities were randomly selected. From these four sub cities a total of six kebeles were selected with simple random sampling technique, then each kebele contributed to the sample size proportional to households. The final households with eligible women were selected on systematic random sampling. Woman of reproductive age group from each selected households were interviewed and only one woman was interviewed for households having two or more reproductive age women on random to prevent intera house hold correlation.

\subsection{Variables}

\subsubsection{Dependent Variables}

The dependent variable of the study was Breast Selfexamination practice. 


\subsubsection{Independent Variables}

The independent variables of the study were:

1) Socio demographic factors: Age, educational status of the respondents, marital status, occupation, monthly income.

2) Health related factors: Family history of breast cancer, knowing someone suffering from breast cancer, previous history of breast disease.

3) Attitude: about breast self-examination practice, benefit and believes about breast self-examination, future intention in practicing breast self-examination and respondents feeling toward practice of breast selfexamination.

4) Knowledge on: Advantage of regular breast selfexamination, age at which breast self-examination has to be begun, when should a woman do breast selfexamination, what to look during breast self-examination.

\subsection{Data Collection Procedures}

A pretested structured questionnaire was used according to the objectives of the study and the local situation of the study area. The data were collected by female nurses and supervised by health officers. Face to face interview was the technique of data collection. Questionnaires were adapted after reviewing different literature of similar studies to collect the data. The questionnaire was prepared in English, and translated in to Amharic and Afaan Oromo language and the final version of the questionnaire was used for data pretest for reliability. Finally the data were collected after obtaining informed consent from the respondents by interviewers.

\subsection{Data Quality Assurance}

Training was given for both data collectors and supervisors for two days including pre-test finding discussion and correction of data collection tools. Pre-test of the questioner was done in non-selected kebeles of Adama town. The questionnaires were examined by experts to the area of study for content validity. The supervisors and principal investigator have closely supervised the performance of the data collectors on a daily basis and the completeness of the questionnaires were thoroughly scrutinized every day at the end of data collection session and any inconsistencies were amended on time.

\subsection{Data Processing and Analysis}

The data were entered to Epi-Info version 7 and exported to SPSS version 20 for data cleaning, recoding and analysis. During the analysis, the responses of 'strongly agree' and 'agree' were classified as agree; responses of 'undecided' was classified as neutral, and responses of 'strongly disagree' and 'disagree' were classified as disagree. The overall agreement level was calculated and individuals with the mean and above the mean score were categorized under "agreement" and others as "disagreement". The analysis employed both descriptive and inferential statistics. Bivariate and multivariable logistic regression analyses were done to determine the preliminary relationship between the independent and dependent variables. Multi co linearity test was carried out to see the correlation between each independent variable, using Variance Inflation Factor (VIF) and tolerance test. Hosmer-Lemeshow goodness-of- fit test was used to assess whether the necessary assumptions for the application of binary logistic regression was fulfilled. Factors associated with breast self- examination practice on bivariate analysis were identified and the variables with $p$-value of $<$ 0.25 on bivariate analyses were entered to multivariable logistic regression to identify the independent predictors of breast self-examination practice. Back ward illumination logistic regression method was used. Finally, 95\% confidence interval not including one with its corresponding $\mathrm{p}$-value less than 0.05 was considered statistically significant. To indicate strength of association, odds ratio was used as a measure of effect and results from the multivariable logistic regression were reported in the form of Adjusted Odds Ratios (AORs).

\subsection{Ethical Considerations}

Ethical clearance was obtained from Institutional Review Board (IRB) of Adama Hospital Medical College. Before commencing data collection, legal permission with letter of support was obtained from Adama town health office. All the study participants were informed about the purpose of the study and their right to refuse. Verbal informed consent was obtained from every respondent and strict confidentiality was also maintained at all level. After completion of the interview health education was given for those who have no information about breast self- examination practice and those who never practiced at all.

\section{Results}

\subsection{Socio-demographic Characteristics}

A total of 786 participants were planned to participate in the study, out of which 765 respondents had responded making the response rate of $97 \%$. The median age of the respondents was 28 years (ranged from 23-34 years). Out of 765 respondents, $477(62.4 \%)$ of the respondents were married, 355 (46.4\%) had above secondary education, 449 $(58.7 \%)$ were orthodox Christians in religion, $330(43.1 \%)$ of them were housewives and $159(20.8 \%)$ of the respondents were unemployed. Average monthly income of the respondents' was 2818.47 Birr.

Table 1. Socio-Demographic characteristics of respondents on Breast SelfExamination Practice and Associated Factors among Women of Reproductive Age in Adama Town, Oromia Regional State, Ethiopia March, 2018 .

\begin{tabular}{lll}
\hline Variables $(\mathbf{n = 7 6 5 )}$ & Category & Frequency $(\%)$ \\
\hline Age distribution (years) & & \\
& $<20$ & $118(15.4)$ \\
& $20-24$ & $122(15.9)$ \\
& $25-29$ & $211(27.6)$ \\
& $30-34$ & $127(16.6)$ \\
& $>35$ & $187(24.4)$ \\
\hline
\end{tabular}




\begin{tabular}{lll}
\hline Variables (n=765) & Category & Frequency (\%) \\
\hline Ethnicity & Oromo & $349(45.6)$ \\
& Amhara & $255(33.3)$ \\
& Gurage & $93(12.2)$ \\
Religion & Other* & $68(8.9)$ \\
& Orthodox & $449(58.7)$ \\
& Protestant & $164(21.4)$ \\
& Muslim & $143(18.7)$ \\
Marital status & Other** & $9(1.2)$ \\
& & \\
& Single & $192(25.1)$ \\
& Married & $477(62.4)$ \\
& Divorced & $44(5.8)$ \\
& Widowed & $52(6.8)$ \\
& & \\
Occupation & Employee & $212(27.7)$ \\
& Housewife & $330(43.1)$ \\
& Daily Laborer & $64(8.4)$ \\
& Unemployed & $159(20.8)$ \\
Educational status & & \\
& No formal education & $77(10.1)$ \\
& Primary education & $93(12.2)$ \\
& Secondary education & $240(31.4)$ \\
& Above secondary education & $355(46.4)$ \\
\hline
\end{tabular}

NB. Others include: * Silte, Wolaeyeta, Argoba, ** Wake feta, Jehovah witness

\subsection{Knowledge of the Respondents}

More than half $440(57.5 \%)$ of respondents' ever heard of breast self-examination practice. Only 152 (19.9\%) knew how frequent breast self-examination practiced. Out of 765 respondents 403 (52.7\%) of them did not know the right time of breast self- examination practice. Only 98 (12.8\%) of the respondents mentioned a week after menses was the right time of breast self-examination practice.

From the above mentioned knowledge status of the respondents, only $17(2.2 \%)$ of the respondents had good knowledge; $167(21.8 \%)$ of the respondents had satisfactory knowledge, and $581(75.9 \%)$ of the respondents had poor knowledge.

Table 2. Knowledge of the respondents on Breast Self-Examination Practice and Associated Factors among Women of Reproductive Age in Adama Town, Oromia Regional State, Ethiopia March, 2018.

\begin{tabular}{ll}
\hline Characteristics (n=765) & Frequency (\%) \\
\hline Heard of breast self-examination & $325(42.5)$ \\
NO & $440(57.5)$ \\
YES & $119(15.6)$ \\
Early detection of breast cancer improve chance of survival \\
NO & $646(84.4)$ \\
YES & \\
How frequent is BSE done? & $152(19.9)$ \\
Correct response (monthly) & $232(30.3)$ \\
Incorrect response (weekly, once in three month, once & $381(49.8)$ \\
in six month) & \\
I don't know & $98(12.8)$ \\
Appropriate time to practice BSE & $264(34.5)$ \\
Correct response (awake after menses) & \\
Incorrect response (before menses, during menses) & \\
\hline
\end{tabular}

\begin{tabular}{ll}
\hline Characteristics (n=765) & Frequency (\%) \\
\hline I don't know & $403(52.7)$ \\
Who should perform BSE? & $156(20.4)$ \\
$<20$ years & $312(40.8)$ \\
$>20$ years & $297(38.8)$ \\
I don't know & \\
Breast cancer can cure in its early stage of disease & $116(15.2)$ \\
NO & $649(84.8)$ \\
YES & \\
presence of breast cancer screening methods & $321(42 \%)$ \\
NO & $444(58 \%)$ \\
YES & \\
position of breast self-examination practice & $586(76.6)$ \\
NO & $179(23.4)$ \\
YES & \\
Over all knowledge of the respondents & $17(2.2)$ \\
Good knowledge & $167(21.8)$ \\
Satisfactory knowledge & $581(75.9)$ \\
Poor knowledge &
\end{tabular}

\subsection{Attitude of the Respondents}

Regarding the attitude of the respondents toward breast self-examination practice, $583(76.2 \%)$ of the respondents had positive attitude and the rest $182(23.8 \%)$ had nonsupportive attitude towards breast self-examination practice.

Table 3. Attitude of the respondents on Breast Self-Examination Practice and Associated Factors among Women of Reproductive Age in Adama Town, Oromia Regional State, Ethiopia March, 2018.

\begin{tabular}{lll}
\hline Questions & Options & Frequency (\%) \\
\hline \multirow{2}{*}{ Attitude } & Positive & $583(76.2)$ \\
& Negative & $182(23.8)$ \\
1. Every women should & Agree & $568(74.2)$ \\
perform BSE & Neutral & $52(6.8)$ \\
& Disagree & $145(19)$ \\
2. The thought of breast cancer & Agree & $556(72.7)$ \\
scares me & Neutral & $25(3.3)$ \\
& Disagree & $184(24)$ \\
3. BSE should be done every & Agree & $602(78.7)$ \\
month & Neutral & $45(5.9)$ \\
& Disagree & $118(15.4)$ \\
4. Women alone capable of & Agree & $576(75.3)$ \\
doing BSE & Neutral & $39(5.1)$ \\
& Disagree & $150(19.6)$ \\
5. Take necessary care for my & Agree & $582(76.1)$ \\
breast & Neutral & $55(7.2)$ \\
& Disagree & $128(16.7)$ \\
\hline
\end{tabular}

\subsection{Practice of the Respondents}

The respondents were asked if they practiced breast selfexamination as a means of early detection measures of diagnosis of breast cancer. Majority of the respondents 393 (51.4\%) replied that they practiced BSE. About 372 (48.6\%) of the respondents did not practice BSE at all. Among the respondents who practiced BSE, $90 \quad(22.9 \%)$ of them practiced BSE monthly. The most common reason for not practicing BSE mentioned by the respondents was not having breast problem 203 (54.6\%) followed by not knowing how to 
do BSE 144 (38.7\%).

Table 4. Practice of the respondents on Breast Self-Examination Practice and Associated Factors among Women of Reproductive Age in Adama Town, Oromia Regional State, Ethiopia March, 2018.

\begin{tabular}{ll}
\hline Variables & Frequency (\%) \\
\hline BSE practice $(\mathrm{n}=765)$ & $372(48.6)$ \\
NO & $393(51.4)$ \\
YES & \\
Frequency of BSE (n=393) & $90(22.9)$ \\
A week after menses (correct response) & $173(44)$ \\
When it comes to my mind & $130(33.1)$ \\
Any time during the month & \\
Barriers to perform BSE a week after menses $(\mathrm{n}=303)$ & $181(59.7)$ \\
Forget fullness & $30(9.9)$ \\
Too busy/not having enough time & $92(30.4)$ \\
I don't think it is important & \\
Reason for not practicing BSE (n=372) & $203(54.6)$ \\
Do not have breast problem & $25(6.7)$ \\
Fear of diagnosed with breast cancer & $144(38.7)$ \\
Lack of knowledge how to practice (BSE) & \\
\hline
\end{tabular}

\subsection{Factors Associated with Breast Self-examination Practice}

Bivariate and multi variable logistic regression analysis were done to assess the determinants of breast selfexamination practice. Variables in bivariate analysis with $\mathrm{p}$ value $<0.25$ were entered to multi variable logistic regression model for analysis. Multivariable logistic regression analysis result showed that Educational status, Fear of breast cancer from family history and knowing someone suffering from breast cancer had shown positive significant association with breast self- examination practice with $\mathrm{p}$ value $<0.05$.

Among socio demographic variables, Educational status of the respondents were statically significant in explaining breast self-examination performance. Above secondary education was positively associated with breast selfexamination practice (AOR, 6.38; 95\% CI: 2.87, 14.16).

This result also shows secondary education was positively associated with breast self-examination practice (AOR, 5.03; 95\% CI: 2.24, 11.31). The current study shows knowledge of someone suffering from breast cancer was positively associated with breast self-examination practice (AOR, 1.98; 95\% CI: 1.28, 3.09). Fear of breast cancer from family history positively associated with breast self-examination practice (AOR, 12.38; 95\% CI: 6.36, 24.11).

Table 5. Factors associated with Breast Self-Examination Practice and Associated Factors among Women of Reproductive Age in Adama Town, Oromia Regional State, Ethiopia March, 2018.

\begin{tabular}{|c|c|c|c|c|}
\hline \multirow{2}{*}{ Characteristics } & \multicolumn{2}{|c|}{ BSE practice } & \multicolumn{2}{|l|}{ Odds Ratio } \\
\hline & NO $(\%)$ & YES (\%) & COR $(95 \% \mathrm{CI})$ & AOR (95\% CI) \\
\hline \multicolumn{5}{|l|}{ Educational status of respondents } \\
\hline No formal education & $66(85.7)$ & $11(14.3)$ & 1: 00 & 1: 00 \\
\hline Primary education & $70(75.3)$ & $23(24.7)$ & $1.97(0.89,4.31)$ & $2.24(0.89,5.67)$ \\
\hline Secondary education & $101(42.1)$ & $139(57.9)$ & $8.26(4.15,16.43)$ & $5.03(2.24,11.31)^{* *}$ \\
\hline Above secondary education & $135(38)$ & $220(62)$ & $9.78(4.99,19.17)$ & $6.38(2.88,14.17)^{* *}$ \\
\hline \multicolumn{5}{|l|}{ Know someone with BC } \\
\hline YES & $46(25)$ & $138(75)$ & $3.84(2.65,5.56)$ & $1.98(1.28,3.09)^{*}$ \\
\hline \multicolumn{5}{|l|}{ Fear of BC from family history } \\
\hline NO & $352(58.7)$ & $248(41.3)$ & 1: 00 & $1: 00$ \\
\hline YES & $20(12.1)$ & $145(87.9)$ & $10.29(6.27,16.88)$ & $12.38(6.36,24.11)^{* *}$ \\
\hline
\end{tabular}

*Statistical significance, NB: *p-value $<0.05$, and **p-value $<0.001,1$ : Reference

Note:-variables not entered in the model because they were not found significant in bivariate analysis.

\section{Discussion}

This community based cross-sectional quantitative study attempted to explore breast self-examination practice and associated factors among reproductive age women in Adama town. Community represents a significant resource for facilitating positive changes in early breast cancer prevention strategies. It is very crucial that women should know how their breasts normally look and feel. Early detection which remains the surest means of breast cancer prevention can be achieved through Breast Self-Examination (BSE). The value of breast self-examination practice in the early diagnosis of breast cancer has been emphasized by several authors $[2,3$, 14, 34].

In this study the overall prevalence of breast selfexamination practice was $51.4 \%$ with $95 \%$ CI $(48.1,55.2)$. This finding is similar with study conducted in Malaysia 54\%, and Mekelle town Ethiopia 53.6\% [4, 20]. It is lower than the finding of the study conducted at kefa zone, Ethiopia $73.07 \%$ and higher than the finding of the study conducted in Nigeria $25 \%$, Kenya $40.9 \%$, [33, 35, 36]. These differences might be due to differences in the study participants, differences in study period, study area and variation in method of analysis like in case of Kefa zone [35].

As educational level of the respondents increases the odds of performing breast self-examination practice also increases. Those who had above secondary education were more likely (about six times) to practice breast self-examination than those who had no formal education. This study also showed that individuals who had secondary education were more likely to practice breast self-examination (about five times) than those who had no formal education. This study is similar with studies from Iranian house wives, Jordanian women, and Ethiopia Mekelle town [4, 26, 28].

This result is incomparable with the studies from Angola. 
The differences between the current study and other studies may be due to differences in study area and study population like the study of Angola where the study population were above 40 years old [27]. The current study indicates as educational levels of the women increase the rates of practice of breast self-examination also increase. The likely hood of performing breast self-examination practice increased by more than 12 times for respondents who have fear of breast cancer from family history from those who have no family history of breast cancer This finding is in line with the findings from Iranian house wives women and the study from Angola [26-28]. This result is incomparable from studies in Ajman [25].

The differences observed between this study and other studies might be due to differences in study population and study area For respondents who know someone suffering from breast cancer the odds of performing breast selfexamination increased by about two times which is higher than their counter parts. This finding is consistent with the findings of the cross sectional study conducted on Jordanian women [26]. Discussion with the community on the issue of breast self-examination practice may have influence on the early diagnosis of breast cancer among child bearing age women.

\section{Strength and Limitation}

\subsection{Strength}

Community based data collection and probability simple random sampling method were used that can represent the community. And the method of data collection and type of data were that increases the study validity and reliability.

\subsection{Limitation of the Study}

Cross-sectional study design has a dis advantage of detecting causal and temporal relationship; there may be social desirability bias by respondents to address all relevant variables. Besides, since the study was conducted in urban area; it may not represent rural community.

\section{Conclusion and Recommendation}

\subsection{Conclusion}

This study showed that the prevalence of breast selfexamination practice was high $(51.4 \%)$. In the current study factors associated with breast self-examination practice were educational status, fear of breast cancer from family history and knowing someone suffering from breast cancer. From the indicators, educational status and fear of breast cancer from family history had strong positive association with breast self-examination practice.

\subsection{Recommendations}

1) Adama Town Health Office, Education Office, Women's And Child Affair Office and regional health bureau shall provide awareness creation on breast selfexamination practice to the women.

2) The cancer associations at regional health bureau shall prepare effective health education programs through mass media like, Television, community Radios/FM radios, awareness campaigns, events like breast cancer days, to elucidate awareness and practice of breast selfexamination.

3) Health care providers shall educate the communities to increase their awareness about BSE.

4) The community and the community leaders shall give serious attention the practice of breast self-examination as early breast cancer screening methods so as to prevent late diagnosis and other complications.

5) Further researches that look into managers' and staff's opinion regarding breast self-examination practice with the emphasis of quantitative study should be conducted taking this study as reference.

\section{Acknowledgements}

I would like to forward my deepest gratitude to Adama town Health office for giving me the necessary information and data. I extend my heartfelt gratitude to Mrs. Meyrema Abdo and Mr. Abebe Megerso who advised me on this study. I also thank my friends for giving me needful peer critique, encouragement and unreserved support. Finally, I would like to extend my sincere acknowledgment to all individuals who participated in this study.

\section{References}

[1] E. C. I. Casmir, N. E. Anyalewechi, I. S. N. Onyeka, A. C. O. Agwu, and N. C. Regina, "Knowledge and Practice of Breast Self-Examination among Female Undergraduates in SouthEastern Nigeria," Health (N. Y.), vol. 07, no. 09, pp. 11341141, 2015, doi: 10.4236/health.2015.79129.

[2] K. Birhane et al., "Practices of Breast Self-Examination and Associated Factors among Female Debre Berhan University Students," Int. J. Breast Cancer, vol. 2017, pp. 1-6, 2017, doi: $10.1155 / 2017 / 8026297$.

[3] S. Ram BihariL al Shrivastava, P. Saurabh Shrivastava, and J. Ramasamy, "Self Breast Examination: A Tool for Early Diagnosis of Breast Cancer," Am. J. Public Health Res., vol. 1, no. 6, pp. 135-139, Jun. 2013, doi: 10.12691/ajphr-1-6-2.

[4] B. Legesse and T. Gedif, "Knowledge on breast cancer and its prevention among women household heads in Northern Ethiopia," Open J. Prev. Med., vol. 04, no. 01, pp. 32-40, 2013, doi: 10.4236/ojpm.2014.41006.

[5] G. Umbreen, C. Jabeen, and M. S. Riaz, "breast selfexamination (bse); knowledge, attitude and practice among post rn nursing students in lahore," Prof. Med. J., vol. 24, no. 03, pp. 453-457, Mar. 2017, doi: 10.17957/TPMJ/17.3745.

[6] T. M. Bs. RGN, Dot Little wood DCR, SRR, PG Cert., Cert. HE, and Jane Jenkinson RGN, "Breast self-examination and breast awareness: a literature review," J. Clin. Nurs., pp. 570578, Sep. 2004. 
[7] Fathia Attia Mohammad1,, Magda Mohammad Bayoumi and, Mona Mohammad Megahed3, "Efficacy of Instructional Training Program in Breast Self-Examination \& Breast Screening for Cancer among University Students," Public Health Res., vol. 3, pp. 71-78, 2013, doi: 10.5923/j.phr.20130303.06.

[8] S. E. Ahmed, N. F. E. Ahmed, and D. Adam, "study to evaluate the knowledge and practices of nurses about breast self-examination (BSE) to screen for breast cancer, in elmak nimer university hospital," Int. J. Res. -GRANTHAALAYAH, vol. 4, no. 1, pp. 27-34, Jan. 2016, doi: 10.29121/granthaalayah.v4.11.2016.2839.

[9] Tazeem Shahbaz and, Khair un Nisa, "knowledge and practice of breast self-examination among antenatal attendees presenting to a tertiary care hospital in karachi, pakistan.," Dep. Community Health Sci. Rashid Latif Med. Coll. Lahore, vol. 4, no. 1, Jun. 2013.

[10] "Cancer in Norway 2015: Cancer Registry of Norway, 2016, 2015.

[11] Danny R. Youlden, Susanna M. Cramb, Cheng Har Yip, and, Peter D. Baade, "Incidence and mortality of female breast cancer in the Asia_Pacific regio," Cancer Biol. Med., vol. 11, Jan. 2014, doi: 10.7497/j.

[12] N. Gangane, N. Ng, and M. S. Sebastian, "Women's Knowledge, Attitudes, and Practices about Breast Cancer in a Rural District of Central India," Asian Pac. J. Cancer Prev., vol. 16, no. 16, pp. 6863-6870, Nov. 2015, doi: 10.7314/APJCP.2015.16.16.6863.

[13] V. Vanderpuye et al., "An update on the management of breast cancer in Africa," Infect. Agent. Cancer, vol. 12, no. 1, Dec. 2017, doi: 10.1186/s13027-017-0124-y.

[14] C. Ikechukwu, "Breast Cancer Knowledge among Women in Ebonyi State, Nigeria: Implication for Women Breast Cancer Education," J. Health Educ. Res. Dev., vol. 03, no. 02, 2015, doi: 10.4172/2380-5439.1000129.

[15] J. O. Faronbi and J. Abolade, "Breast self - examination practices among female secondary school teachers in a rural community in Oyo State, Nigeria," Open J. Nurs., vol. 02, no. 02, pp. 111-115, 2012, doi: 10.4236/ojn.2012.22017.

[16] O. I. Neji, E. E. Esienumoh, U. V. Kalu, and E. O. Bamidele, "Breast cancer awareness and practice of breast-selfexamination among women in Adiabo community in Odukpani local government area of Cross River State, Nigeria," Clin. Nurs. Stud., vol. 4, no. 1, Dec. 2015, doi: 10.5430/cns.v4n1p50.

[17] Wondemagegnhu Tigeneh, Abera Molla, Ayenalem Abreha, and Mathwose, and Assefa, "Pattern of Cancer in Tikur Anbessa Specialized Hospital Oncology Center in Ethiopia from 1998 to 2010," Int. J. Cancer Res. Mol. Mech., vol. 1.1, May 2015, doi: http://dx.doi.org/10.16966/2381-3318.103.

[18] Tefera B, Assefa M, Abebe B, and and Rauch D, "Patterns of Cancer in University of Gondar Hospital: North-West Ethiopia," J. Oncol. Med. Pract., vol. 1, no. 2, Nov. 2016.

[19] H. Gerensea et al., "The Impact of Cancer in the Tigray Region of Ethiopia: A Secondary Analysis," J. Cancer Sci. Ther., vol. 09, no. 03, 2017, doi: 10.4172/1948-5956.1000447.

[20] Khairunnisa Shallwani et al., "Self Examination for Breast and Testicular Cancers: A Community-based Intervention
Study," Asian Pac. J. Cancer Prev., vol. 11, p. 11 (1), 145-8., Jan. 2010.

[21] Ndura, Elizabeth Wambui, "Breast self-examination practice for early detection of breast cancer among women of reproductive age seeking family planning services at Mbagathi Services at Mbagathi District Hospital, Nairobi, Kenya," 2012, [Online]. Available: http://erepository.uonbi.ac.ke:8080/xmlui/handle/123456789/8 303.

[22] Mary Atanga Bi Suh and, Julius Atashili, Eunice Asoh Fuh and Vivian Ayamba Eta1, "Breast Self-Examination and breast cancer awareness in women in developing countries: a survey of women in Buea, Cameroon," Dep. Nurs. Fac. Health Sci. Univ. Buea Buea Cameroon 2 Dep. Public Health Hyg. Fac. Health Sci. Univ. Buea Buea Cameroon, Nov. 2012 , doi: 10.1186/1756-0500-5-627.

[23] S. A. R. Al-Dubai, K. Ganasegeran, A. M. Alabsi, M. R. A. Manaf, S. Ijaz, and S. Kassim, "Exploration of Barriers to Breast-Self Examination among Urban Women in Shah Alam, Malaysia: A Cross Sectional Study," Asian Pac. J. Cancer Prev., vol. 13, no. 4, pp. 1627-1632, Apr. 2012, doi: 10.7314/APJCP.2012.13.4.1627.

[24] P. D. S. A. A. M. Jawaher A. Bin Jumah MSN, RN Ph. D... M Sc. N., B. Sc. N., "Knowledge \& Practice of Saudi Women about the Prevention of Breast Cancer," Int. J. Appl. Sci. Technol., vol. 3, p. 2, Feb. 2013.

[25] S. S. Al-Sharbatti, R. B. Shaikh, E. Mathew, and M. A. S. AlBiate, "Breast Self-Examination Practice and Breast Cancer Risk Perception among Female University Students in Ajman," Asian Pac. J. Cancer Prev., vol. 14, no. 8, pp. 4919-4923, Aug. 2013, doi: 10.7314/APJCP.2013.14.8.4919.

[26] Blanche I. Mikhail, DNSc, R. N., C. N. S. and Wasileh PetroNustus, Sc. D., R. N., "Factors Associated with Breast SelfExamination among Jordanian Women," _ Blackwell Publ. Inc, vol. 19, pp. 263-271, Aug. 2002.

[27] H. dos P. Tavares, S. B. M. P. Tavares, F. A. Natanel, and D. P. Capingana, "Knowledge and Attitude of Patients, and Practice of the Arrest of Breast Cancer in Outpatient Consultations in Mastology at the General Hospital of Huambo, Angola," Clin. Med. Insights Womens Health, vol. 8, p. CMWH.S21320, Jan. 2015, doi: $10.4137 /$ CMWH.S21320.

[28] Seyed Abolhassan Naghibi et al., "Sociocultural Factors Associated with Breast-Self-Examination among Iranian Women," Dep. Health Educ. Promot. Sch. Public Health Inst. Public Health Res. Tehran Univ. Med. Sci. Tehran Iran, vol. 53, 2015.

[29] V. S., R. Kollipaka, and R. R, "The knowledge and attitude of breast self-examination and mammography among rural women," Int. J. Reprod. Contracept. Obstet. Gynecol., pp. 1511-1516, 2015, doi: 10.18203/23201770.ijrcog20150738.

[30] F. O. K. G. K. OSAGBEMI, "knowledge, attitude and practice of breast self-examination among female secondary school teachers in ilorin, nigeria,” (C) Eur. J. Sci. Res., vol. 10, 2005.

[31] I. A. Avci, "Factors associated with breast self-examination practices and beliefs in female workers at a Muslim community," Eur. J. Oncol. Nurs, vol. 12, no. 2, pp. 127-133, Apr. 2008, doi: 10.1016/j.ejon.2007.11.006. 
[32] M. Azage, G. Abeje, and A. Mekonnen, "Assessment of Factors Associated with Breast Self-Examination among Health Extension Workers in West Gojjam Zone, Northwest Ethiopia," Int. J. Breast Cancer, vol. 2013, pp. 1-6, 2013, doi: $10.1155 / 2013 / 814395$.

[33] Global Burden of Disease Cancer Collaboration et al., "Global, Regional, and National Cancer Incidence, Mortality, Years of Life Lost, Years Lived With Disability, and DisabilityAdjusted Life-years for 32 Cancer Groups, 1990 to 2015: A Systematic Analysis for the Global Burden of Disease Study," JAMA Oncol., vol. 3, no. 4, p. 524, Apr. 2017, doi: 10.1001/jamaoncol.2016.5688.

[34] Lei Wang, MOT, "Breast Cancer Screening Practices and Associated Factors among Chinese-Australian Women Living in Sydney,” The University of Sydney, Sydney, 2016.

[35] N. Birhane, A. Mamo, E. Girma, and S. Asfaw, "Predictors of breast self - examination among female teachers in Ethiopia using health belief model," Arch. Public Health, vol. 73, no. 1, Dec. 2015, doi: 10.1186/s13690-015-0087-7.

[36] M. Tafa Segni and D. M. Tadesse, "Breast Self-examination: Knowledge, Attitude, and Practice among Female Health Science Students at Adama Science and Technology University, Ethiopia," Gynecol. Obstet., vol. 06, no. 04, 2015, doi: 10.4172/2161-0932.1000368.

[37] S. T. Dellie, "Knowledge About Breast Cancer Risk-Factors, Breast Screening Method And Practice Of Breast Screening Among Female Healthcare Professionals Working In Governmental Hospitals, Addis Ababa, Ethiopia," IOSR J. Pharm. Biol. Sci., vol. 2, no. 1, pp. 5-12, 2012, doi: 10.9790/3008-0210512.

[38] "Latest world cancer statistics Global cancer burden rises to 14.1 million new cases in 2012: Marked increase in breast cancers must be addressed.” Dec. 12, 2013. 